Psychosocial Safety Climate. Some specific organisational variables emerged has the significant impact on perceived distress. Discussion CISF Personnel requires a comprehensive Stress Assessment that helps to focus on required behavioural competencies to improve upon and also will enable effective implementation and continual improvement of the policies and practices. It necessitates stress safety net which will in turn provide necessary stress management programmes, counselling services and staff welfare planning to promote employee work-life balance and organisational excellence.

\section{THE INVOLVEMENT OF THE EMPLOYEES IN THE PROJECT MANAGEMENT: A KEY ISSUE FOR EFFICIENCY AND HEALTH AT WORK}

B Dugué* , J Petit. Researcher in ergonomics, University of Bordeaux, Bordeaux-INP, IMS, France

\subsection{6/oemed-2018-ICOHabstracts. 1640}

Introduction The design of working places fitting for all the employees is a major issue for the prevention of health and safety. It is a double challenge: because of the target, the result of the design, but also regarding the methods of intervention. The management of changes is a way to promote a learning and collaborative organisation, and thus the role of the final users. The participation of the employees in the design process is an important issue to achieve these goals, but it is a complex process which needs several requirements. The involvement of employees can lead to failure if the conditions and the aim of the participation is not clear enough.

Methods An ergonomic intervention aiming the design of a reception desk for 280 agencies of a bank company has been carried out. After two attempts which led the company to a social conflict, they decided to start over the process with an ergonomist, with a different management. A steering group and a working group had been set up, simulations and test period had been carried out.

Results The result of the design and it acceptance by the employees show that the process is as important as the goal. We can attest that several conditions must be controlled: which structure of the project, who to be involved, how, for what regarding their professional position, with which knowledge of the real work situations?

Conclusion The way we build the interventions must be in link with our vision of the future operation and the place of the users in the organisations. The project structure must insure two goals: the involvement of the relevant managers and the participation of the employees concerned by the implementation, but with tools and a methodology. It is both a matter of efficiency and a dynamic for healthy organisations.

\section{SUBSIDIARITY AS A TARGET FOR HEALTHY ORGANISATIONS}

J Petit*, B Dugué. Researcher in ergonomics, University of Bordeaux, Bordeaux-INP, IMS, France

10.1136/oemed-2018-ICOHabstracts. 1641
Introduction Corporate governance, through the involvement of employees and the dynamics that it can produce, is an essential issue for efficiency and for safeguarding workers' health. Many studies have shown that individual autonomy is a determining factor for occupational health. Employees must have individual and collective leeway in organising their work, not only applying procedures that have been defined by others but being able to show their creativity and influence their work environment. In this aim, organisational design should provide the opportunity to influence management modes, distribution of power, individual participation in the design processes. The concept of subsidiarity can help to achieve these goals.

Methods From an ergonomic intervention in an insurance company about the organisation of a call centre, we can see what are the conditions to build an organisation aiming at subsidiarity, both as a target and as a process for the management of change.

Results Contrary to the idea of a predetermined definition of all the decisions that can be taken at every level of the hierarchy, efficiency consists in constantly adapting the level of decision-making to the problem being dealt with. This requires constructing an organisation which is sensitive to details of events, which can be always adjusting the levels at which matters are dealt with. However, this swing from one decision level to another is only possible if the organisation and the people within it are well prepared beforehand.

Conclusion The concept of subsidiarity constitutes an ethical point of reference for dealing with questions of organisational design and corporate governance. It favours decision-making at the lowest appropriate level by following three organising principles: the competency principle, the assistance principle, and the substitution principle. The way we build the interventions must be in line with this vision. It is both a matter of efficiency and a dynamic for healthy organisations.

\section{MOBILE PHONE USE AND MENTAL HEALTH - A REVIEW}

Sara Thomée* ${ }^{*}$ Department of Occupational and Environmental Medicine, University of Gothenburg and Sahlgrenska University Hospital, Gothenburg, Sweden

\subsection{6/oemed-2018-ICOHabstracts. 1642}

Introduction Mobile phones have in a few decades affected how we communicate, interact, search for information, and pass time, at work and at leisure, implying a near ubiquitous use. There is a growing literature on potential health effects of mobile phone use. The aim was to review epidemiological studies that take a psychological or behavioural perspective on mobile phone use and mental health.

Methods PubMed and PsycINFO were searched for studies on mobile phone use and mental health in May 2, 2016. 1550 papers were screened on title/abstract. Exclusion criteria: studies considering electromagnetic fields, attention while driving/ studying, relational aspects, sexual behaviour, cyberbullying, case or experimental studies, and reviews. 176 papers were retrieved of which 126 were included. Formal systematic quality assessment of the papers was not done.

Results Only approx 5\% of the papers had longitudinal design. Self-report was the dominating method of measurement for exposure and outcomes. One third of the studies concerned children or youth. The majority of studies on 
adults were based on university students and/or self-selected participants. In summary, intense or frequent mobile phone use was seen to be associated with a broad spectrum of mental health outcomes, e.g. depressive symptoms and sleep problems. Mobile phone use at bedtime was associated with shorter sleep duration and lower sleep quality. 'Problematic use', i.e., mobile phone use connected to behavioural addiction or pathological usage, was associated with several negative outcomes such as depression, anxiety, and sleep problems. Discussion Research studies show associations between mobile phone use and mental health outcomes. However, there is need for more studies of good quality; with longitudinal design, objective measurements, and well-defined study populations, in order to draw valid conclusions about possible causal associations between mobile phone use and mental health symptoms.

\section{A CLINICAL APPROACH OF WORKAHOLISM}

Quentin Durand-Moreau, Brice Loddé, Jean-Dominique Dewitte. Occupational and Environmental Diseases Centre, University Hospital of Brest, Brest, France

\subsection{6/oemed-2018-ICOHabstracts. 1643}

Introduction To date, no definition of workaholism can be considered as consensual. Some authors propose a behavioural approach with a cognitive side (an inner drive) and a behavioural side (working excessively). But with this perspective, the place for subjectivity is rather small and clinical descriptions of workaholism are scarce. In this context, we aimed to describe case-reports of patients suffering from workaholism. Methods We describe case-reports from patients who went to the occupational disease centre of Brest University Hospital, France between November 2013 and July 2016. Consultations were performed by a single physician, specialised in workrelated mental disorders with the methods of clinical occupational medicine, as described by Davezies. Included patients were those with a diagnostic of workaholism. The diagnostic has been performed regarding Goodman's common criteria of addictions.

Results During the period of interest, 168 patients have consulted for a work-related mental trouble. Of these, 8 patients suffered from workaholism (4 female and 4 male). Mean age at diagnostic time was 44.1 years. Three clinical situations will be detailed: a 41 years old door-to-door canvasser selling goods for craft workers, a 51 years old nurse in a hospital, and a 30 years old saleswoman in a cooperative selling farming goods.

Discussion Clinical descriptions allow to highlight some characteristic elements among patients suffering from workaholism: variable remuneration linked to the worker's commercial performance, the use of a professional telephone during weekends and free time, storage of professional stuff at home, huge ambivalence between the will to go on working while knowing that work is degrading health, addictive comorbidities (tobacco, alcohol consumption, anorexia). There is a need for a work sociopsychologic approach of the situation, associating individual healthcare and improvements on the working environment. The latter part is often lacking but it offers the best long-term efficacy.

\section{WHICH PSYCHOSOCIAL RISK FACTORS AT WORK CONTRIBUTE TO THE ONSET OF STRESS-RELATED DISORDERS? A SYSTEMATIC REVIEW AND META- ANALYSIS}

GJ de Groene* ${ }^{*}$ K Nieuwenhuijsen, MH Frings-Dresen, HF van der Molen. Academic Medical Centre, Department Coronel Institute of Occupational Health/Netherlands Centre for Occupational Diseases, Amsterdam Public Health research institute, Amsterdam, The Netherlands

\subsection{6/oemed-2018-ICOHabstracts. 1644}

Introduction Psychosocial risk factors at work are known to contribute to the onset of stress-related disorders (SRDs). Evidence about work-related psychosocial risk factors is necessary to select and implement preventive workplace interventions. The aim of our review was to identify psychosocial risk factors at work which are associated with the onset of SRDs, updating a prior review with evidence up until 2008.

Methods A systematic literature search was conducted for the period January 2008 to October 2014 in Medline, Embase and PsycINFO. Inclusion criteria were: prospective study design, exposure of workers to psychosocial risk factors, and an SRD outcome. Data from the studies included were pooled with the results of a previous systematic review. The quality of the evidence was assessed using an adapted GRADE procedure.

Result The updated review consisted of twelve studies. The search yielded 5300 articles. Five articles met the inclusion criteria and were added to the seven of the previous review.

Evidence of high quality was found for the risk factors of 'effort-reward imbalance', 'high psychological demands', 'low decision authority', 'low co-worker support', 'low supervisor support', 'low procedural justice' and 'low relational justice', while evidence of moderate quality was found for 'high emotional demands' contributing to the onset of an SRD.

'Effort-reward imbalance' and 'low procedural justice' exhibited the largest association with SRDs, with Odds Ratios of 2.0 (95\% CI: 1.81 to 2.22 ) and 1.8 (95\% CI: 1.60 to 1.98), respectively.

Discussion Several psychosocial work-related risk associated with the onset of SRDs were established, confirming prior findings. Awareness of these risk factors could be the starting point for the selection of preventive interventions to reduce work-related SRDs.

\section{A STUDY ON JOB STRESS AND RELATED HEALTH PROBLEMS AMONG HOSPITAL NURSES IN INDIA}

Bishwadeep Paul*. Siemens Ltd, Mumbai, India

\subsection{6/oemed-2018-ICOHabstracts. 1645}

Introduction Stress in nurses is an endemic problem. It contributes to health problems in nurses and decreases their efficiency. Documenting the causes and extent of stress in any healthcare unit is essential for successful interventions. This exploratory study attempted to establish the existence and extent of work stress in nurses in a hospital setting, to identify the major sources of stress, and to find the incidence of psychosomatic illness related to stress. In addition it was 